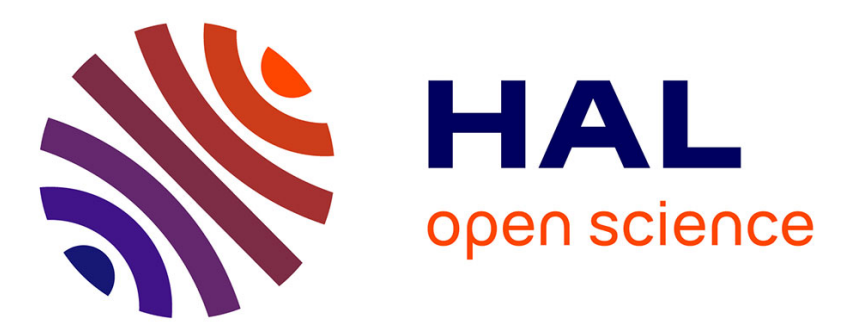

\title{
Mechanical properties of ceria-calcia stabilized zirconia ceramics with alumina additions
}

D. Tovar-Vargas, E. Roitero, M. Anglada, E. Jiménez-Piqué, H. Reveron

\section{To cite this version:}

D. Tovar-Vargas, E. Roitero, M. Anglada, E. Jiménez-Piqué, H. Reveron. Mechanical properties of ceria-calcia stabilized zirconia ceramics with alumina additions. Journal of the European Ceramic Society, 2021, 41 (11), pp.5602-5612. 10.1016/j.jeurceramsoc.2021.05.006 . hal-03439306

\section{HAL Id: hal-03439306 https://hal.science/hal-03439306}

Submitted on 22 Nov 2021

HAL is a multi-disciplinary open access archive for the deposit and dissemination of scientific research documents, whether they are published or not. The documents may come from teaching and research institutions in France or abroad, or from public or private research centers.
L'archive ouverte pluridisciplinaire HAL, est destinée au dépôt et à la diffusion de documents scientifiques de niveau recherche, publiés ou non, émanant des établissements d'enseignement et de recherche français ou étrangers, des laboratoires publics ou privés. 


\title{
Mechanical Properties of Ceria-Calcia stabilized Zirconia Ceramics with Alumina Additions.
}

\author{
Tovar-Vargas D. ${ }^{1,2 *}$, Roitero E. ${ }^{3}$, Anglada M., ${ }^{1,2}$ Jiménez-Piqué E. ${ }^{1,2}$, \\ Reveron $\mathrm{H}^{3}$
}

\begin{abstract}
${ }^{I}$ CIEFMA Department of Material Science and Engineering EEBE, Universitat Politècnica de Catalunya, C/ Eduard Maristany, 10-14, 08019, Barcelona, Spain.
\end{abstract}

2 Barcelona Research Center in Multiscale Science and Engineering, Universitat Politècnica de Catalunya, C/Eduard Maristany, 10-14, 08019, Barcelona, Spain.

${ }^{3}$ Univ Lyon, CNRS, INSA Lyon, UCBL, MATEIS, UMR5510, 69621 Villeurbanne, France.

Abstract

Ceria-stabilized zirconia-based composites have been developed aiming to obtain ceramic materials with enhanced hardness, strength, fracture toughness, and resistance to low temperature degradation. These composites are based on ceria-calcia stabilized zirconia $\left(10 \mathrm{~mol} \% \mathrm{CeO}_{2}-1\right.$ $\mathrm{mol} \% \mathrm{CaO} \mathrm{TZP})$ and $\alpha$-alumina $(0-15 \mathrm{wt} \%)$ as a second phase. Raw materials in the form of powders were dispersed through ball milling, dried by slip casting and subsequently grounded before being pressed and conventionally sintered at $1450^{\circ} \mathrm{C}$. Compared to the strength and hardness of 10Ce-TZP ceramics (typically $500 \mathrm{MPa}$ and $6 \mathrm{GPa}$ ), an increase was observed for all compositions, especially for $10 \mathrm{Ce}-1 \mathrm{CaO}-5 \mathrm{Al}_{2} \mathrm{O}_{3}(739 \mathrm{MPa}$ and $10.2 \mathrm{GPa})$. Single Edge VNotched Beam fracture toughness values ranged from 5.1 to $6.6 \mathrm{MPa} \cdot \sqrt{\mathrm{m}}$, indicating a loss of transformability for all compositions. As in 10Ce-1CaO-TZP co-doped ceramics, the aging resistance of all alumina containing composites was also excellent.

\section{Introduction}

Zirconia is one of the most used advanced ceramic materials due to its high strength and fracture toughness $\left(K_{I c}\right)$, resulting from the tetragonal $(t)$ to monoclinic $(m)$ martensitic phase transformation that can be triggered under stresses [1]. Oxides stabilizers are employed to retain the tetragonal phase in a metastable state at ambient temperature because it is not stable at room temperature. Currently, yttria $\left(\mathrm{Y}_{2} \mathrm{O}_{3}\right)$ is the most common stabilizer used in zirconia, and normally, $3 \mathrm{~mol} \%$ additions are sufficient to stabilize it. This ceramic is known as 3Y-TZP for 3 mol\% Yttria Tetragonal Zirconia Polycrystals, and it has been used in the development of hip femoral heads in the past. Unfortunately, under humid conditions, 3Y-TZP ceramics may be prone to low temperature degradation (LTD, also known as aging). LTD occurs at relatively low temperatures and in humid environments by the action of water species that can penetrate the bulk material. The water species can reduce the oxygen vacancies present in Y-TZP, destabilizing the metastable tetragonal zirconia grains, and the volume increment associated to phase change creates local stresses and micro-cracks close to the surface [2-5], which finally may cause the material to fracture prematurely [6]. This phenomenon was responsible for a significant number of femoral head failures in recently implanted patients and, consequently, for the suspension of its use in orthopedics from 2001 [7, 8]. Nevertheless, zirconia is considered a good candidate for 
the development of dental implants due to its excellent biocompatibility and aesthetic appearance and has since been used in the dental field [7,9].

In the last years, the use of ceria stabilized zirconia (Ce-TZP) has been proposed as an alternative material to the Y-TZP and its aging drawback. Due to the tetravalent character of cerium, zirconia can be stabilized without generating oxygen vacancies, leading to an increase in LTD resistance. Moreover, the tetragonal phase of Ce-TZP with less than $12 \mathrm{~mol} \%$ ceria is more easily transformable so that high $K_{I c}$ values can be reached. Nevertheless, compared to 3Y-TZP ceramics, it has lower strength (around $500 \mathrm{MPa}$, compared to $1000 \mathrm{MPa}$ for Y-TZP), which is partly related to its larger grain size ( $\sim 2 \mu \mathrm{m}$ compared to $\sim 0.3 \mu \mathrm{m}$ for Y-TZP) [7]. Unfortunately, grain boundaries mobility is much higher in Ce-TZP, and fine-grained and fully dense materials are not easily obtained by sintering [10]. In order to reduce the grain size of Ce-TZP ceramics, several studies have shown the positive effect of adding a second phase, commonly $\alpha$-alumina, which acts as reinforcement by inhibiting the grain growth, hence, improving the mechanical properties like strength and hardness. Depending on the processing characteristics, different types of composites can be obtained at the nano or micro-nano scale $[11,12]$.

Another approach for enhancing the mechanical properties of Ce-TZP ceramics is suppressing the grain growth by co-doping with relatively small concentrations of divalent cations. Divalent cations of large ionic radius like $\mathrm{Ca}^{2+}$ in small concentrations have a strong effect on grain growth kinetics and grain boundary segregation of 12Ce-TZP [13]. Thus, the mobility of grain boundaries is strongly reduced by the addition of divalent cations, with $\mathrm{Ca}^{2+}$ having a stronger effect among the divalent ions studied because of its larger ionic radius. In our study, $\mathrm{CaO}$ is added to ceriastabilized zirconia-based composites in order to further refine the microstructure since other authors have found that small amounts of divalent cations have suppressed the grain growth of 12Ce-TZP based materials within the solubility limits [14].

Table 1 summarizes the strength and $K_{I c}$ of Ce-TZP/based composites reported in the literature. The strength values depend on the composition. Generally, the reported values of $K_{I c}$ are higher when measured by the VIF method. Although this method is the easiest and faster to be implemented, allowing also the estimation of $K_{I c}$ in small volumes $[15,16]$, it has raised some concerns, as deformation, transformation, or crack patterns produced by indentation may deviate from the assumptions of the model [17, 18]. In the literature, several methods have been proposed for determining the $K_{I c}$ of ceramics: Vickers Indentation Fracture Toughness (VIF), Single Edge V-Notched Beam (SEVNB), Surface Crack in Flexure (SCF), Single Edge Precracked Beam (SEPB), Chevron Notch Beam (CNB) [19], Shot-Rod [20], and Double Cantilever Beam (DCB) [21]. SEPB and CNB methods are not widely used due to the difficulty in their measuring or their high cost. On the contrary, thanks to the facility and/or low cost, one of the most popular methods to evaluate $K_{I c}$ is by means of Vickers indentations (VIF) [15]. It is based on measuring the length of cracks generated at the four corners of the Vickers imprint, in a well-polished surface, at a given applied load. There are many empirical equations to calculate $K_{I c}$ values by using the VIF method [22, 23]. Among them, equations proposed by Niihara et al. [24] (Palmqvist type cracks) and Anstis et al. [25] (radial-median cracks) are widely used. In transformable ceramics, the indentation cracks are usually of Palmqvist type, so that Niihara equation for Palmqvist cracks seems more appropriate for tough ceramics. However, the equation can be applied only as far as the ratio between crack length and indentation semi-diagonal are in a specific range. The crack length should obey the requirement of $0.25<(l / a)<2.5$ (where $l$ is the average of the four cracks length that are generated in the four corners of the Vickers indentation and $a$ is half the length of the average indentation diagonal), otherwise the computed $K_{I c}$ will be wrongly estimated [24].

By contrast, the SEVNB method is well established from a fracture mechanics point of view as far as a very sharp notch can be machined at the center of a prismatic bar perpendicularly to its 
length. High notch sharpness needs to be achieved for a reliable measurement of $K_{I c}$ in submicron grain size ceramics $[19,26]$.

Therefore, in transformable zirconia-based materials, it is necessary to assess $K_{I c}$ by using robust techniques. In this context, the aim of the present work is to process, by means pressing and conventional sintering methods, $10 \mathrm{Ce}$-TZP co-stabilized with $1 \mathrm{~mol} \%$ of calcia $(\mathrm{CaO}) /$ alumina composites (2.5-15 wt\%) in the form of bending bars to characterize the effect of microstructural features and composition on the mechanical behavior, (especially the hardness, strength and $K_{I c}$ ). Additionally, as these types of zirconia-based ceramics can be good candidates for structural biomedical applications, their LTD behavior is also studied by accelerated aging tests in an autoclave. In a recent work [27], we have shown that these composites can be processed by pressing and conventional sintering, using commercially available powders. The maximum mechanical strength (around $1000 \mathrm{MPa}$, measured by the ball-on-three ball test) was reached in samples containing $1 \mathrm{~mol} \% \mathrm{CaO}$ and $10 \mathrm{wt} \%$ of alumina $(98.3 \%$ relative density and $\sim 0.7 \mu \mathrm{m}$ zirconia grain size). In this work, a different processing route was implemented to prepare bigger samples (bending bars) with improved relative density, and the $K_{I c}$ and the strength were characterized by the SEVNB and three-point bending tests, respectively. Dealing with highly transformable ceramics, able of being plastically deformed during testing, the influence of the testing method is significant [28]. Finally, in order to be able to compare with our previous results [27], the raw materials, as well as the compositions of composites prepared in the present study, have been kept identical.

Table 1. Strength and fracture toughness of Ce-TZP/alumina composites.

\begin{tabular}{|c|c|c|c|c|c|}
\hline Reference & Material & $\begin{array}{l}\text { Strength } \\
(\mathrm{MPa})\end{array}$ & Method* & $\begin{array}{l}\text { Fracture } \\
\text { Toughness } \\
(\mathrm{MPa} \cdot \sqrt{\mathrm{m}})\end{array}$ & Method \\
\hline Sato et al.[29] & $\begin{array}{c}12 \mathrm{Ce}-\mathrm{TZP}+(10-20 \\
\left.\mathrm{wt} \% \mathrm{Al}_{2} \mathrm{O}_{3}\right)\end{array}$ & $620-760$ & $3 \mathrm{P}$ & $14-17$ & VIF \\
\hline Tsai et al.[2 & $\begin{array}{l}12 \mathrm{Ce}-\mathrm{TZP}+(10-20 \\
\left.\mathrm{wt} \% \mathrm{Al}_{2} \mathrm{O}_{3}\right)+\mathrm{MnO}\end{array}$ & $273-648$ & $4 \mathrm{P}$ & $6.5-8.5$ & Short Rod \\
\hline $\mathrm{Cu}$ & $\begin{array}{c}12 \mathrm{Ce}-\mathrm{TZP} / 30 \\
\text { vol } \%+\mathrm{SrO}\end{array}$ & 726 & $4 \mathrm{P}$ & 15.1 & $\begin{array}{c}\text { Double } \\
\text { Cantilever }\end{array}$ \\
\hline Nawa et al. & $\begin{array}{c}10 \mathrm{Ce}-\mathrm{TZP} / 30 \mathrm{vol} \% \\
\mathrm{Al}_{2} \mathrm{O}_{3}+0.05 \mathrm{~mol} \% \\
\mathrm{TiO}_{2}\end{array}$ & 950 & $3 \mathrm{P}$ & 18.3 & VIF \\
\hline Tanaka et al.[31] & $\begin{array}{c}\mathrm{Al}_{2} \mathrm{O}_{3}+0.05 \mathrm{~mol} \% \\
\mathrm{TiO}_{2} \\
10.5 \mathrm{Ce}-\mathrm{TZP}+8 \text { vol\% }\end{array}$ & 941 & $3 \mathrm{P}$ & 20.05 & VIF \\
\hline Reveron et al.[32] & $\begin{array}{c}\mathrm{Al}_{2} \mathrm{O}_{3}+8 \text { vol\% } \\
\mathrm{SrAl}_{12} \mathrm{O}_{19} \\
11 \mathrm{Ce}-\mathrm{TZP}+8 \text { vol\% }\end{array}$ & 1197 & P3B & 10.2 & SEVNB \\
\hline Touaiher et al.[28] & $\begin{array}{c}\mathrm{Al}_{2} \mathrm{O}_{3}+8 \text { vol\% } \\
\mathrm{SrAl}_{12} \mathrm{O}_{19}\end{array}$ & 738 & $4 \mathrm{P}$ & 10.6 & SEVNB \\
\hline
\end{tabular}




\section{Materials and Methods}

\subsection{Processing of powders}

Commercially available 10Ce-TZP powder $\left(\mathrm{ZrO}_{2} 10 \mathrm{~mol} \% \mathrm{CeO}_{2}\right.$, Daiichi CEZ-10), $1 \mathrm{~mol} \% \mathrm{CaO}$ powder (Calcium Oxide Sigma-Aldrich) and $\alpha$-alumina powder (Tamicron TM-DAR, Taimei Chemicals Co.) were used as starting powders. The physical properties of the starting powders for 10Ce-TZP and $\alpha$-alumina have been described elsewhere [33]; the mean particle sizes after stirring in water for five days were 250 and $270 \mathrm{~nm}$, respectively. The mean particle size of the $\mathrm{CaO}$ powders was in the range of $10-35 \mu \mathrm{m}$ as observed by scanning electron microscopy (SEM) [34].

Five aqueous suspensions containing $20 \mathrm{vol} \%$ solid load were prepared in which the amount of $10 \mathrm{~mol} \%$ ceria-stabilized zirconia (10-Ce-TZP) and calcia (1 mol\% with respect to zirconia, afterward named $1 \mathrm{CaO}$ ) powders were kept constant, and the alumina content was varied as 0 , 2.5, 5, 10 and $15 \mathrm{wt} \% \mathrm{Al}_{2} \mathrm{O}_{3}$ with respect to $(10 \mathrm{Ce}+1 \mathrm{CaO})$. The matrix and composite powders prepared are hereinafter referred to as $10 \mathrm{Ce}-1 \mathrm{CaO}$ and $10 \mathrm{Ce}-1 \mathrm{CaO}-\mathrm{XAl}_{2} \mathrm{O}_{3}$, where $\mathrm{X}$ represents the percentage (wt\%) of $\alpha$-alumina. Suspensions were mixed for 6 hours using ball-milling and 3Y-TPZ grinding beads. To promote the deagglomeration between particles, $3 \mathrm{wt} \%$ of Darvan 821-A (with respect to the total powder weight added) was used as a dispersant. Afterward, the suspensions were poured into alumina porous molds and left to dry for 72 hours in a humiditycontrolled chamber at room temperature [35]. The as-prepared green-body parts were then subjected to grinding (agate mortar) and sieving (100 $\mu \mathrm{m}$ mesh size).

\subsection{Processing of samples: shaping, sintering, machining, and grinding}

Plates of $50 \times 50 \times 4 \mathrm{~mm}^{3}$ were uniaxially pressed at $50 \mathrm{MPa}$ and then cold isostatic pressed (CIP) at $300 \mathrm{MPa}$. As-pressed samples were pressureless sintered. During sintering, the thermal treatment started with a debinding step $\left(1^{\circ} \mathrm{C} / \mathrm{min}\right.$ until $600^{\circ} \mathrm{C}$ for 1 hour $)$ followed by a heating ramp at a rate of $5^{\circ} \mathrm{C} / \mathrm{min}$ until the sintering temperature $\left(1450^{\circ} \mathrm{C}\right)$ holding for 1 hour, and decreasing the temperature at the same rate. After sintering, four prismatic bars of $4 \times 3 \times 40 \mathrm{~mm}^{3}$ were machined for each composition with the aim of performing mechanical tests. In case of the beading test, faces to be subjected to tensile stresses were grounded and polished using diamond paste down to $1 \mu \mathrm{m}$.

\subsection{Microstructural, mechanical, and aging characterization}

Relative density was calculated by the relationship between experimental and theoretical density, calculated by Archimedes' method and the rule of mixtures, respectively. Microstructural features were characterized by SEM (SEM-Zeiss SUPRA VP55) performed on surfaces polished down to $1 \mu \mathrm{m}$ with diamond suspension followed by a finishing step with $0.03 \mu \mathrm{m}$ silica nanoparticles. In this way, it was possible to reveal the grains at low voltage without applying a metallic coating. The average grain size of zirconia and alumina were computed from these micrographs using the linear intercept method [36] without any correction factor.

Vickers hardness $\left(H V_{30}\right)$ was measured on polished surfaces (Vickers Testwell FV-700). The average value for each composition was obtained from five indentations and converted to SI units $(\mathrm{GPa})$. To estimate the quantity of $t-m$ stress-induced phase transformation, the size of the transformed area observed around each Vickers imprint was calculated and the average computed. The size of the transformed area was approximated to the circle traced from the center of the 
imprint, and encompassing, the uplifted area observed by optical microscopy (Nomarski interference contrast mode).

Elastic modulus of samples with a rectangular cross-section $\left(4 \times 3 \times 40 \mathrm{~mm}^{3}\right)$ was evaluated by the resonance frequency method using a Grindo-Sonic tester. After supporting the prismatic bar at its nodes of resonance and generating a small impact at the center with a steel ball harm, the fundamental resonant frequency of vibration was recorded by a microphone located beneath the specimen. The elastic modulus is determined using equation (1) that relates the resonant frequency and the geometry of the sample [37].

$$
E=0.946424 \cdot 10^{-10} \cdot \frac{m}{w} \cdot\left(\frac{L}{b}\right)^{3} \cdot f^{2} \cdot f_{c}
$$

where $E$ is the elastic modulus (GPa), $m$ is the mass of the sample $(\mathrm{g}) ; b$ is the thickness $(\mathrm{mm})$; $w$ the bar width $(\mathrm{mm})$ and $L$ the length of the bar $(\mathrm{mm}), f$ is the frequency $(\mathrm{Hz})$ and $f_{c}$ is the shape factor (dependent on Poisson's ratio). Four bars of each composition were tested to obtain the average value.

The fracture toughness $\left(K_{I c}\right)$ was calculated through the SEVNB technique. All samples were prepared according to the ISO standard 6872 [38] (required dimensions: 4 × 3 x $40 \mathrm{~mm}^{3}$ ). They were notched in the $3 \mathrm{~mm}$ bar side using a diamond cutting disk of $300 \mu \mathrm{m}$ of thickness. The depth of the notch was around $0.5 \mathrm{~mm}$. To sharpen the notch depth, a razor blade was used along with a diamond paste of $3 \mu \mathrm{m}$ until reaching the depth required by the ISO standard 6872 (in the range of 0.8-1.2 mm). An optical microscope (Zeiss, Axiophot) was employed to check the final notch length. Finally, to release the residual stresses caused by the notch preparation, the samples were annealed $\left(1200^{\circ} \mathrm{C}\right.$ for 30 minutes with a heating/cooling rate of $\left.5^{\circ} \mathrm{C} / \mathrm{min}\right)$. A four-point bending (4P) fixture with outer and inner span lengths of $L=35 \mathrm{~mm}$ and $\mathrm{l}=10 \mathrm{~mm}$, was employed using a universal hydraulic testing machine (Instron 8500, USA). The load was applied until the sample failure using a speed load of $0.5 \mathrm{~mm} / \mathrm{min}$. Four bars $4 \times 3 \times 40 \mathrm{~mm}^{3}$ of each composition were tested and the average SEVNB $K_{I c}$ calculated.

Equation (2) was used to measure $K_{I c}$ by the SENVB method in four-point bending:

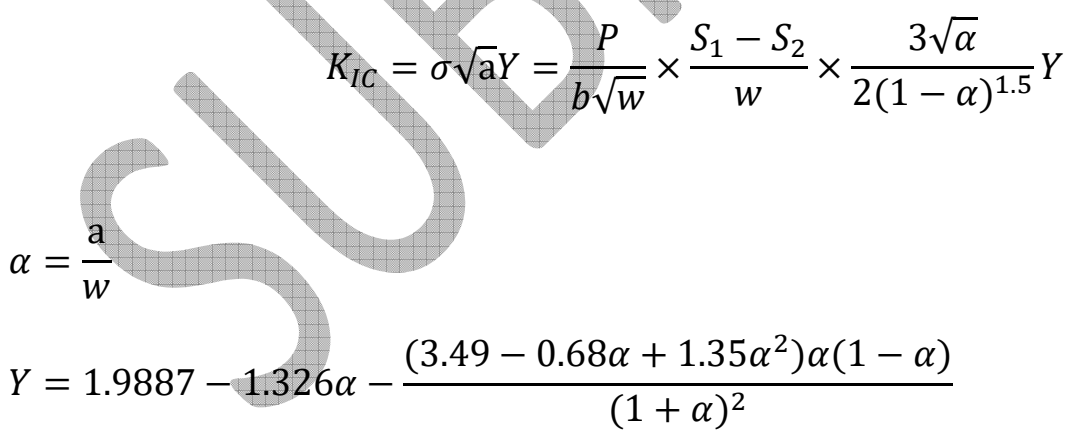

where,

$\sigma$ is the fracture strength, a is the average notch depth, $P$ is the fracture load, $b$ is the bar thickness, $w$ is the bar width, $S_{1}, S_{2}$ are the support spans $\left(S_{1}>S_{2}\right), \alpha$ is the relative V-notch depth, and $Y$ is the stress intensity shape factor. Four bars of each composition were broken to obtain the average $K_{I c}$ value.

To further assess the transformability of these composites, the $K_{I c}$ was also evaluated using the VIF method [17] from the dimensions of cracks generated at the corners of the indents after Vickers indentations performed at $490 \mathrm{~N}$ load. The indentation cracks being very probably of Palmqvist type, Niihara et al. [24] equation (3) was employed to calculate VIF $K_{I c}$; Anstis et al. 
[25] equation (4) was also used, although it applies to radial-median cracks, in order to show the difference between them when calculating the fracture toughness. Five indentations of each composite were considered to obtain the average value.

$$
\begin{aligned}
K_{I C} & =0.0089 \cdot\left(\frac{E}{H}\right)^{2 / 5} \cdot \frac{F}{a \cdot l^{1 / 2}} \\
K_{I C} & =0.016 \cdot \frac{F}{c^{3 / 2}}\left(\frac{E}{H}\right)^{1 / 2}
\end{aligned}
$$

where $F$ is the applied load, $E$ is the elastic modulus, $H$ is the Meyers hardness calculated as the load divided by the projected area, $a$ is the half of the average diagonal indentation, $l=(c-a)$ is the average of the four cracks length that are generated in the four corners of the Vickers indentation and $c$ is the crack length from the center of the indentation to the crack tip.

Flexural bending strength was measured by three-point bending (3P) with a span of $15 \mathrm{~mm}$ using the half bars left after the fracture toughness tests $4 \times 3 \times 20 \mathrm{~mm}^{3}$. Hence, eight bars of each composition were broken to obtain the average flexural strength value. Faces subjected to tensile stresses were chamfered and polished again down to $1 \mu \mathrm{m}$.

To calculate the flexural strength by three-point bending, equation (5) was used:

$$
\sigma=\frac{3 P L}{2 w b^{2}}
$$

where $\sigma$ is the flexural strength, $P$ is the breaking load, $L$ is the test span, $w$ is the bar width (perpendicular to the applied load), and $b$ is the bar thickness (side parallel to the applied load). The geometry of the samples both for the determination of $K_{I c}$ and flexural strength is presented in Fig. 1.
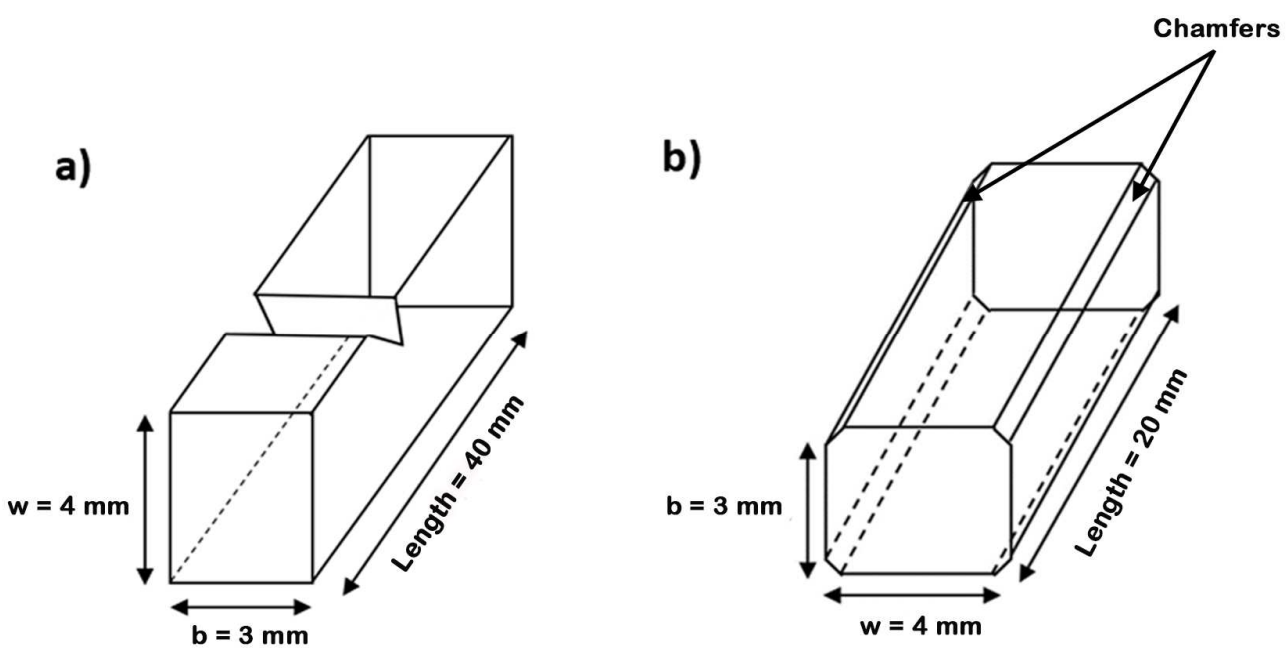

Fig. 1. Samples geometries for determination of a) $K_{I c}$ by the SEVNB method and b) flexural strength by three-point bending.

The monoclinic content in the samples was estimated by $\mathrm{X}$-Ray diffraction $\left(\mathrm{Cu} \mathrm{K}, 10-70^{\circ}\right.$ range in $2 \theta$, step size $0.05^{\circ}$, time for step 5s, Philips PW 1710 diffractometer) performed on surfaces 
polished down to $1 \mu \mathrm{m}$. The volume fraction of the monoclinic phase $\left(V_{m}\right)$ was estimated from equation (6) proposed by Garvie et al. [39] and modified by Toraya et al. [40].

$$
V_{m}=\frac{1.311 X_{m}}{1+0.311 X_{m}} \quad X_{m}=\frac{\left.\left.\left[I_{m}(-111)\right)+I_{m}(111)\right)\right]}{\left.\left.\left[I_{m}(-111)\right)+I_{m}(111)\right)\right]+I_{t}(101)}
$$

where $I_{m}$ and $I_{t}$ are the intensity of the monoclinic and tetragonal peaks, respectively.

Finally, accelerated aging tests were carried out in an autoclave at $134^{\circ} \mathrm{C}$ and 2 bars of pressure for 24 and 60 hours, and the quantity of monoclinic phase on aged surfaces was estimated as described above. This test in an autoclave allows to extrapolate the sample behavior in vivo since it has been shown that 1 hour under these conditions would have the same effect as around 3 to 4 years at $37^{\circ} \mathrm{C}$ (the body temperature) [41].

\section{Results and Discussion}

\subsection{Microstructural features of composites}

The relative densities of as-sintered ceramics are shown in Table 2. All the composites reached full densification in agreement with SEM observations (Fig. 2). Compared to our previous work in which ceramics were obtained using a similar shaping method (i.e., uniaxial pressing at 50 $\mathrm{MPa}, \mathrm{CIP}$ at $288 \mathrm{MPa}$, and pressureless sintering at $1450^{\circ} \mathrm{C}-2$ hours) [27], but by different powder processing, the degree of densification was improved in all sintered ceramics. The new processing method employed here allowed the preparation of almost fully dense $10 \mathrm{Ce}-1 \mathrm{CaO}$ TZP based composites, regardless of their composition. The fact of drying the dispersed suspensions by slipcasting effectively avoided the creation of hard agglomerates, improving in this manner the packing of particles during pressing.

Table 2. Final density and grain size of $10 \mathrm{Ce}-1 \mathrm{CaO}$ and $10 \mathrm{Ce}-1 \mathrm{CaO}-\mathrm{Al}_{2} \mathrm{O}_{3}$ composites after sintering at $1450^{\circ} \mathrm{C}$ for 1 hour. The typical grain size of 10Ce-TZP is also reported from [34].

\begin{tabular}{ccccc}
\hline Sample & $\begin{array}{c}\text { Relative } \\
\text { Density } \\
(\%)\end{array}$ & $\begin{array}{c}\text { Average zirconia } \\
\text { grain size } \\
(\mu \mathrm{m})\end{array}$ & $\begin{array}{c}\text { Average alumina } \\
\text { fine grain size } \\
\text { distribution } \\
(\mu \mathrm{m})\end{array}$ & $\begin{array}{c}\text { Average alumina } \\
\text { coarse grain size } \\
\text { distribution } \\
(\mu \mathrm{m})\end{array}$ \\
\hline $10 \mathrm{Ce}-\mathrm{TZP}$ & - & $1.99 \pm 0.75[34]$ & - & - \\
$10 \mathrm{Ce}-1 \mathrm{CaO}$ & 99.7 & $1.2 \pm 0.1$ & - & - \\
$10 \mathrm{Ce}-1 \mathrm{CaO}-2.5 \mathrm{Al}_{2} \mathrm{O}_{3}$ & 99.8 & $0.8 \pm 0.1$ & $0.3 \pm 0.1$ & $3.1 \pm 1.2$ \\
$10 \mathrm{Ce}-1 \mathrm{CaO}-5 \mathrm{Al}_{2} \mathrm{O}_{3}$ & 99.9 & $1.0 \pm 0.1$ & $0.4 \pm 0.2$ & $6.8 \pm 1.9$ \\
$10 \mathrm{Ce}-1 \mathrm{CaO}-10 \mathrm{Al}_{2} \mathrm{O}_{3}$ & 99.8 & $0.9 \pm 0.1$ & $0.5 \pm 0.3$ & $6.9 \pm 0.8$ \\
$10 \mathrm{Ce}-1 \mathrm{CaO}-15 \mathrm{Al}_{2} \mathrm{O}_{3}$ & 99.9 & $0.8 \pm 0.1$ & $0.3 \pm 0.1$ & $10.1 \pm 1.5$ \\
\hline
\end{tabular}

In terms of grain size, the zirconia average grain size decreases with the presence of calcia from $\sim 2 \mu \mathrm{m}$ in pure 10Ce-TZP to $1.2 \mu \mathrm{m}$ in $10 \mathrm{Ce}-1 \mathrm{CaO}$ (See Table 2 ). This reduction in grain size is not as large as reported in previous works by Turon-Viñas et al. [34] (i.e., $\sim 0.5 \mu \mathrm{m}$ ) and TovarVargas et al. [27] (i.e., $\sim 0.6 \mu \mathrm{m}$ ). In these two works, the powders were processed by milling and dried trough rotary evaporator following by steaming, instead of applying a slip-casting drying step. In agreement with computed final densities, SEM images of Fig. 2 do not reveal the presence of porosity and show a duplex microstructure [42], fine $(<0.5 \mu \mathrm{m})$ and coarse $(>3 \mu \mathrm{m})$ alumina grains were observed in all composite ceramics (see Table 2). 

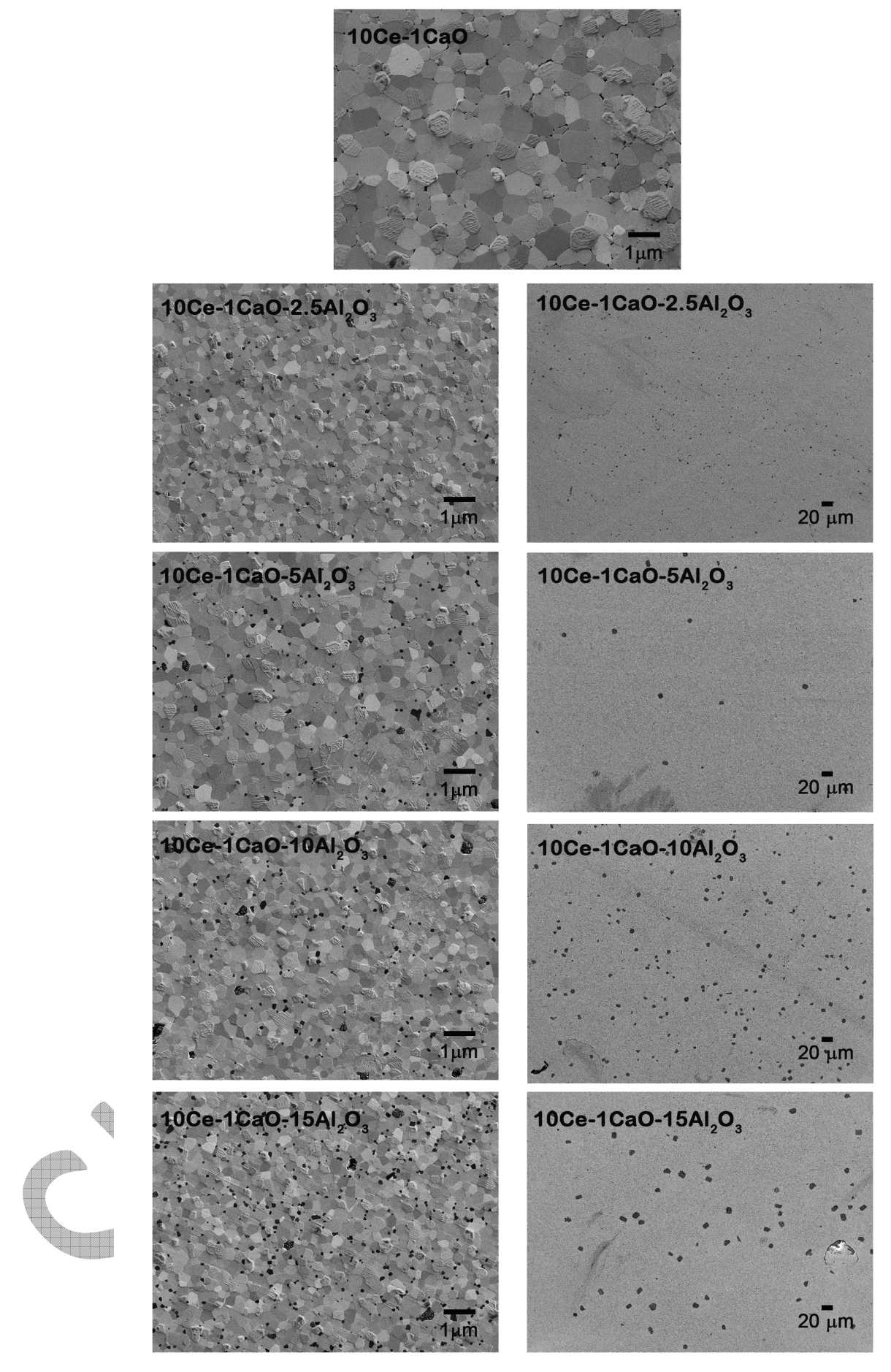

Fig. 2. SEM images of ceria-calcia stabilized zirconia and its alumina-containing composites (2.5 to $15 \mathrm{wt} \%$ ). Two different populations of alumina grains were identified having average sizes of $<\sim 0.3-0.5 \mu \mathrm{m}$ and $>\sim 3-10 \mu \mathrm{m}$.

As seen in Fig. 2, fine and coarse alumina grains appear embedded in the zirconia matrix. While the size of the finest alumina grains seems to be independent of the composite composition, the higher the alumina content, the larger is the size of the bigger grains (see Table 2). The agglomeration of alumina particles resulting in grains of several microns reduces the available 
amount of alumina fine particles in the composites and, consequently, the pinning effect preventing zirconia grain growth. As a result, the expected increasing pinning effect with the alumina content $(5,10$, and $15 \mathrm{wt} \%$ alumina) was not observed. The smallest grain size was obtained in composites 2.5 and $15 \mathrm{Al}_{2} \mathrm{O}_{3}$ (i.e., zirconia grains size of $0.8 \mu \mathrm{m}$ ). With the processing method here employed, the microstructure obtained consists of a duplex microstructure [42], a matrix of $10 \mathrm{Ce}-1 \mathrm{CaO}$ zirconia in which alumina grains are located mainly at the grain boundaries, and a few fine zirconia and alumina grains are occupying intragranular positions (interintragranular composites) as schematized in Fig. 3. However, studying the effect of these clusters of alumina nanoparticles given raise a large grains was not the scope of this work. In future work, it would be interesting to verify this effect on the mechanical properties of the material. For example, in improving the fracture toughness by the crack deflection mechanism.

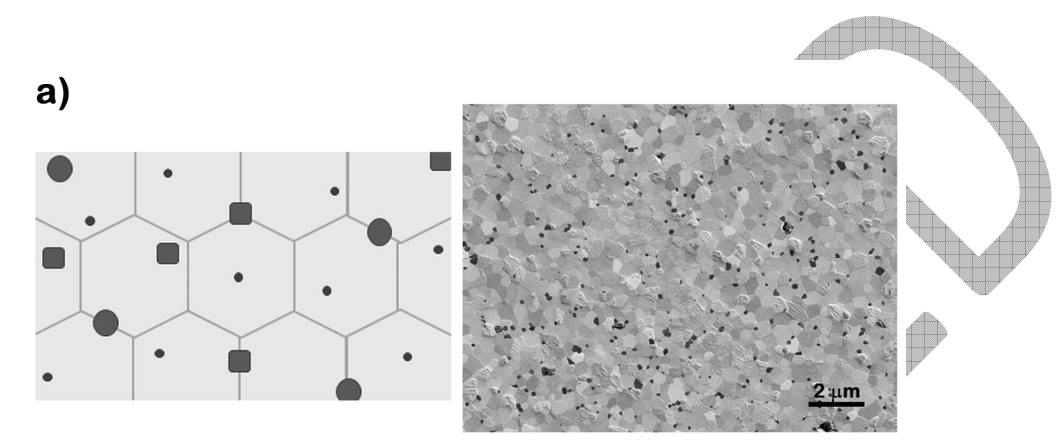

b)
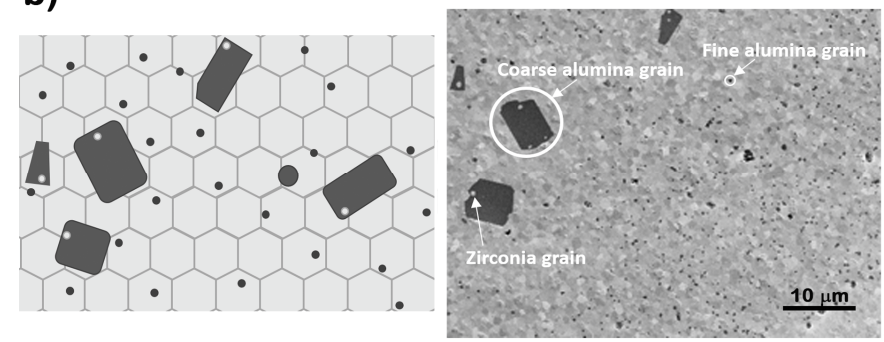

Fig. 3. Composite microstructure of $10 \mathrm{Ce}-1 \mathrm{CaO}-\mathrm{Al}_{2} \mathrm{O}_{3}$ composites. It is a mixture of these two types of composites: a) Micro/nanocomposite in which small black rounded and squared particles are $\alpha$-alumina, and the grey grains correspond to the ceria-calcia stabilized zirconia matrix and $b$ ) Duplex particles of $\alpha$-alumina are embedded in ceria-calcia stabilized zirconia matrix. The illustrative schemes shown on the left side of the figure were adapted from [43].

\subsection{Mechanical properties}

Table 3 summarizes the values obtained for the mechanical properties such as hardness, fracture toughness, flexural strength, and elastic modulus. As a comparison, the values of the mechanical properties measured for 10Ce-TZP are also reported in Table 3. 
Table 3. Mechanical properties of ceria-calcia stabilized zirconia composites with alumina additions.

\begin{tabular}{|c|c|c|c|c|c|c|c|}
\hline \multirow[t]{3}{*}{ Sample } & \multirow{3}{*}{$\begin{array}{c}\text { Average } \\
\text { zirconia } \\
\text { grain size } \\
(\mu \mathrm{m})\end{array}$} & \multirow[t]{3}{*}{$\begin{array}{l}\text { Hardness } \\
\text { (GPa) }\end{array}$} & \multicolumn{3}{|c|}{$\begin{array}{l}\text { Fracture Toughness } \\
\qquad(\mathrm{MPa} \cdot \sqrt{\mathrm{m}})\end{array}$} & \multirow[t]{3}{*}{$\begin{array}{c}\text { Flexural } \\
\text { Strength }^{\S} \\
(\mathrm{MPa})\end{array}$} & \multirow[t]{3}{*}{$\begin{array}{c}\text { Elastic } \\
\text { Modulus } \\
(\mathrm{GPa})\end{array}$} \\
\hline & & & \multirow[t]{2}{*}{$\mathrm{SEVNB}^{\dagger}$} & \multicolumn{2}{|c|}{ VIF* } & & \\
\hline & & & & Anstis & Niihara & & \\
\hline 10Ce-TZP & $1.6^{*}$ & $6.2^{* *}$ & $14^{*}$ & - & - & $504^{*}$ & $190^{*}$ \\
\hline $10 \mathrm{Ce}-1 \mathrm{CaO}$ & $1.2 \pm 0.1$ & $9.9 \pm 0.2$ & $6.5 \pm 0.3$ & $12.9 \pm 0.6$ & $15.2 \pm 1.2$ & $742 \pm 131$ & $195 \pm 16$ \\
\hline $10 \mathrm{Ce}-1 \mathrm{CaO}-2.5 \mathrm{Al}_{2} \mathrm{O}_{3}$ & $0.8 \pm 0.1$ & $10.6 \pm 0.1$ & $5.1 \pm 0.3$ & $11.4 \pm 0.6$ & $12.7 \pm 0.9$ & $571 \pm 90$ & $193 \pm 7$ \\
\hline $10 \mathrm{Ce}-1 \mathrm{CaO}-5 \mathrm{Al}_{2} \mathrm{O}_{3}$ & $1.0 \pm 0.1$ & $10.2 \pm 0.1$ & $6.2 \pm 0.7$ & $9.4 \pm 0.2$ & $10.2 \pm 0.2$ & $739 \pm 30$ & $189 \pm 6$ \\
\hline $10 \mathrm{Ce}-1 \mathrm{CaO}-10 \mathrm{Al}_{2} \mathrm{O}_{3}$ & $0.9 \pm 0.1$ & $10.2 \pm 0.2$ & $6.6 \pm 0.4$ & $11.0 \pm 0.9$ & $12.0 \pm 1.1$ & $685 \pm 125$ & $200 \pm 20$ \\
\hline $10 \mathrm{Ce}-1 \mathrm{CaO}-15 \mathrm{Al}_{2} \mathrm{O}_{3}$ & $0.8 \pm 0.1$ & $10.3 \pm 0.1$ & - & $10.5 \pm 1.1$ & $11.9 \pm 1.7$ & $556 \pm 188$ & $167 \pm 14$ \\
\hline
\end{tabular}

\subsubsection{Vickers Hardness and Elastic Modulus}

The evolution of Vickers hardness with alumina content is depicted in Fig. 4. The values of hardness for $3 \mathrm{Y}-\mathrm{TZP}, 10 \mathrm{Ce}-\mathrm{TZP}$, and 10Ce-CaO base material were taken from the literature are also presented in this figure for comparison. The hardness of the matrix $(10 \mathrm{Ce}-1 \mathrm{CaO}$, grain size $1.2 \mu \mathrm{m}$ ) is $9.9 \mathrm{GPa}$. This represents a strong increase when compared to a hardness of $6.2 \mathrm{GPa}$ measured in pure 10Ce-TZP material presented by Turon-Vinas et al. [34] with a grain size of $\sim 2.0 \mu \mathrm{m}$. The hardness enhancement can be related to the reduction of the grain size resulting from the addition of calcia. However, compared to other zirconia ceramics, for example 3Y-TZP with a grain size of $\sim 0.2 \mu \mathrm{m}$ and a Vickers hardness of $\sim 13.0 \mathrm{GPa}$ [44], 10Ce-1CaO based composites are less hard. For similar ceria-calcia co-stabilized ceramics (11.9 GPa for a grain size of $\sim 0.5 \mu \mathrm{m}$ [34] or $10.4 \mathrm{GPa}$ for $\sim 0.6 \mu \mathrm{m}$ [27]), in agreement with the minor grain size refinement here obtained, the composition of the matrix $(10 \mathrm{Ce}-1 \mathrm{CaO})$, hardness is lower than that reported. The grain size reduction in Ce-TZP ceramics co-stabilized with calcia is attributed to solid-solution formation showing lower grain-boundary mobility. Based on the measured zirconia grain sizes of the composites (Table 2), only small differences in hardness are expected as zirconia grain size is always in the range $0.8-1.0 \mu \mathrm{m}$ for all composites [44].

When alumina is added to $10 \mathrm{Ce}-1 \mathrm{CaO}$, hardness increases due to the composite effect (alumina being harder than zirconia) and the refinement of the microstructure (zirconia grain size). The maximum value of hardness is found in the $10 \mathrm{Ce}-1 \mathrm{CaO}-2.5 \mathrm{Al}_{2} \mathrm{O}_{3}$ composition $(10.6 \mathrm{GPa})$, where a zirconia grain size of $0.8 \mu \mathrm{m}$ was estimated. However, this value remains lower than that obtained by Tovar-Vargas et al.[27] of $12.3 \mathrm{GPa}$ for a zirconia grain size of $\sim 0.4 \mu \mathrm{m}$. In the ceramic composites prepared within this study, hardness remains almost constant for 5, 10, and $15 \mathrm{wt} \%$ of $\mathrm{Al}_{2} \mathrm{O}_{3}$ additions (10.2-10.3 GPa) since alumina particles were partially agglomerated in bigger grains and all these composites present similar zirconia grain sizes and relative density.

The values of the elastic modulus with the addition of alumina are shown in Table 3. The elastic modulus remains almost constant and in the range of 189-200 GPa. Elastic modulus estimated in $10 \mathrm{Ce}-1 \mathrm{CaO}$ and 2.5 to $10 \mathrm{wt} \%$ of $\mathrm{Al}_{2} \mathrm{O}_{3}$ composites are in agreement with those measured in 10Ce-TZP based material (190 GPa [37]) and Ce-TZP alumina composites (200 GPa [30]), corroborating the excellent densification and microstructural characteristics here achieved. 


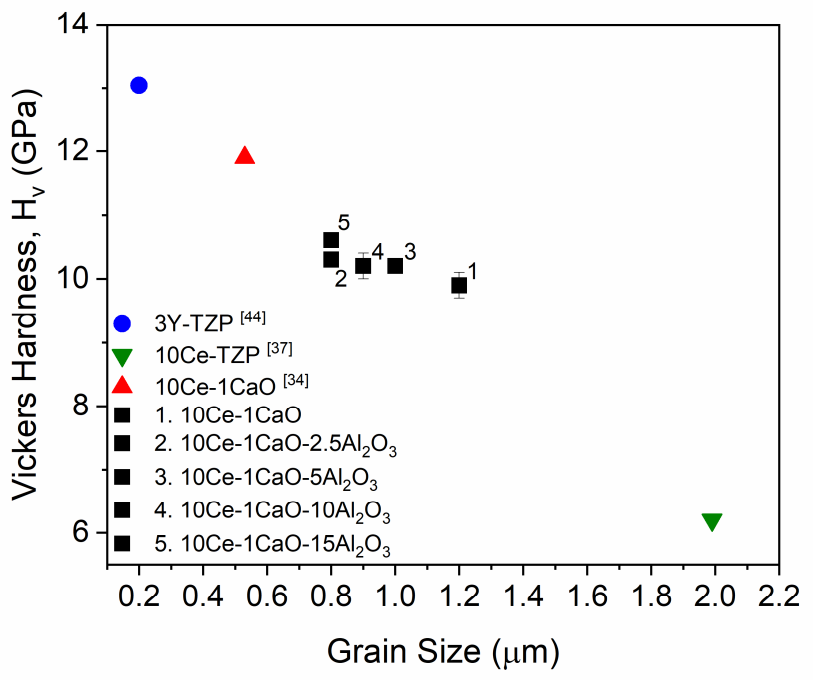

Fig. 4. Vickers hardness of $10 \mathrm{Ce}-1 \mathrm{CaO}$ based composites as a function of grain size. The blue fill circle, the green fill inverse triangle, and the red fill triangle represent the Vickers hardness of $3 \mathrm{Y}-\mathrm{ZP}, 10 \mathrm{Ce}-\mathrm{TZP}$, and $10 \mathrm{Ce}-1 \mathrm{CaO}$ base material taken from references [44] [37], and [34], respectively.

\subsubsection{Transformed area}

After the Vickers hardness tests carried out at $294 \mathrm{~N}\left(H V_{30}\right)$, an uplifted surface was observed in all the composites, indicating that the stress-induced $t-m$ phase transformation took place (see Fig. 5 left). For the sake of comparison, the transformation features of 10Ce-TZP are also depicted in Fig. 5 right. In contrast to what is observed in 10Ce-TZP material (large branched transformation zone without any crack at the corner of the imprint), $10 \mathrm{Ce}-1 \mathrm{CaO}$ and all the composites studied exhibited smaller transformed zones around the indentation imprints.

The transformability of the matrix is hardly affected by the alumina content in the studied range (see Fig. 5 right). The strong reduction in $t-m$ phase transformation in $10 \mathrm{Ce}-1 \mathrm{CaO}$ with respect to Ce-TZP can be associated with both the stabilization of tetragonal zirconia by calcia and the grain size refinement. However, no further appreciable reduction in the size of the transformation zone is detected despite a further grain size refinement from $1.2 \mu \mathrm{m}$ in $10 \mathrm{Ce}-1 \mathrm{CaO}$ ceramic to $1.0-0.8$ $\mu \mathrm{m}$ in alumina-containing composites. 

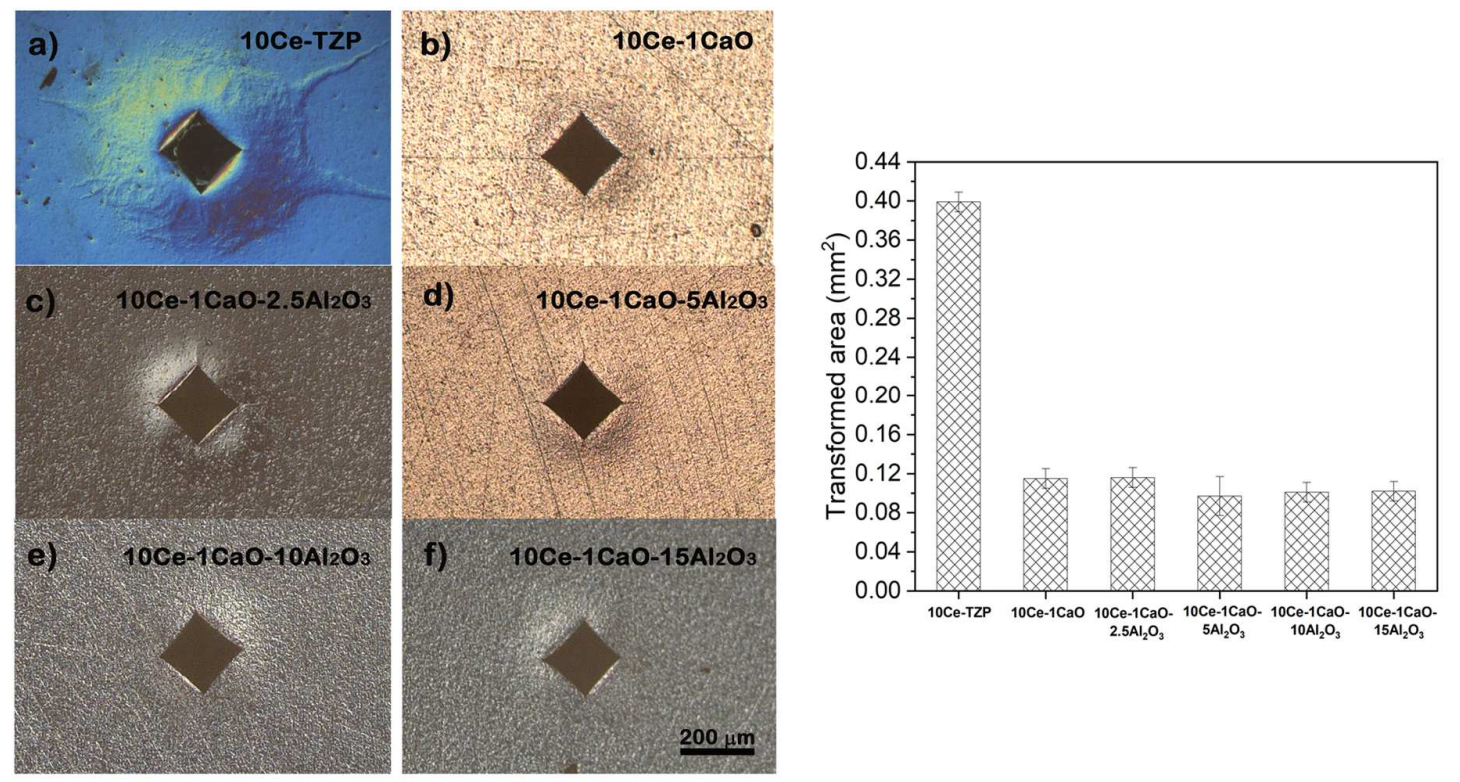

Fig. 5. Left: Nomarski images of Vickers imprints of : a) 10Ce-TZP [33], b) $10 \mathrm{Ce}-1 \mathrm{CaO}$, c) $10 \mathrm{Ce}-$ $1 \mathrm{CaO}-2.5 \mathrm{Al}_{2} \mathrm{O}_{3}$, d) $10 \mathrm{Ce}-1 \mathrm{CaO}-5 \mathrm{Al}_{2} \mathrm{O}_{3}$, e) $10 \mathrm{Ce}-1 \mathrm{CaO}-10 \mathrm{Al}_{2} \mathrm{O}_{3}$ and f) $10 \mathrm{Ce}-1 \mathrm{CaO}-15 \mathrm{Al}_{2} \mathrm{O}_{3}$. A larger transformation is obtained in $10 \mathrm{Ce}-\mathrm{TZP}$ based material, while for $10 \mathrm{Ce}-1 \mathrm{CaO}$ and its composites ( 2.5 to $15 \mathrm{wt} \%$ of $\mathrm{Al}_{2} \mathrm{O}_{3}$ ), the transformability decreases and remains almost the same. Right: Estimated transformed area of 10Ce-TZP, $10 \mathrm{Ce}-1 \mathrm{CaO}$, and its composites with different alumina additions after the Vickers test $(294 \mathrm{~N})$.

\subsubsection{Fracture toughness and flexural strength}

The relationship between the $K_{I c}$ (SEVNB method) and the grain size of $10 \mathrm{Ce}-1 \mathrm{CaO}$ based material and its alumina-containing composites are shown in Fig. 6 . The values of $K_{I c}$ for $3 \mathrm{Y}$ TZP, 10Ce-TZP, and 10Ce-CaO base material taken from the literature are also presented in this figure for comparison. As suggested by the sizes of the transformed areas discussed before, $K_{I c}$ of pure $10 \mathrm{Ce}-\mathrm{TZP}$ is higher than for $10 \mathrm{Ce}-1 \mathrm{CaO}$ and its composites (i.e., $14 \mathrm{MPa} \cdot \sqrt{\mathrm{m}}$ in $10 \mathrm{Ce}-\mathrm{TZP}$ vs. less than $6.6 \mathrm{MPa} \cdot \sqrt{\mathrm{m}}$ ). The $K_{I_{c}}$ for $10 \mathrm{Ce}-1 \mathrm{CaO}$ and its alumina composites are rather similar, except for $2.5 \mathrm{wt} \% \mathrm{Al}_{2} \mathrm{O}_{3}$, for which it is about $20 \%$ lower and related to its smaller grain size $(5.1 \mathrm{MPa} \cdot \sqrt{\mathrm{m}}, 0.8 \mu \mathrm{m})$. The grain sizes for 5 and $10 \mathrm{wt} \%$ alumina compositions increased slightly ( 1 and $0.9 \mu \mathrm{m}$, respectively), and also their transformability in comparison to $10 \mathrm{Ce}-1 \mathrm{CaO}-$ $2.5 \mathrm{Al}_{2} \mathrm{O}_{3}$. The SEVNB fracture toughness of $10 \mathrm{Ce}-1 \mathrm{CaO}-15 \mathrm{Al}_{2} \mathrm{O}_{3}$ was not measured within this work due to the difficulty of obtaining long and flawless bending samples. In general, the processing of composites without processing defects becomes critical as the amounts of secondary phases increase. We noted a poorer pressability for this last composition.

The fracture toughness values here measured are comparable to the $K_{I c}$ observed in 3Y-TZP for similar grain sizes (i.e., in the range of 5 to $6 \mathrm{MPa} \cdot \sqrt{\mathrm{m}}$ ) [7, 44]. In addition, the fact that the incorporation of only $1 \mathrm{~mol} \%$ of $\mathrm{CaO}$ to $10 \mathrm{Ce}-\mathrm{TZP}$ drops $K_{I c}$ to roughly half $(6.5 \mathrm{MPa} \cdot \sqrt{\mathrm{m}})$ can be attributed to the strong refinement of grain size by relatively low addition of calcia and the corresponding reduction in transformability. 


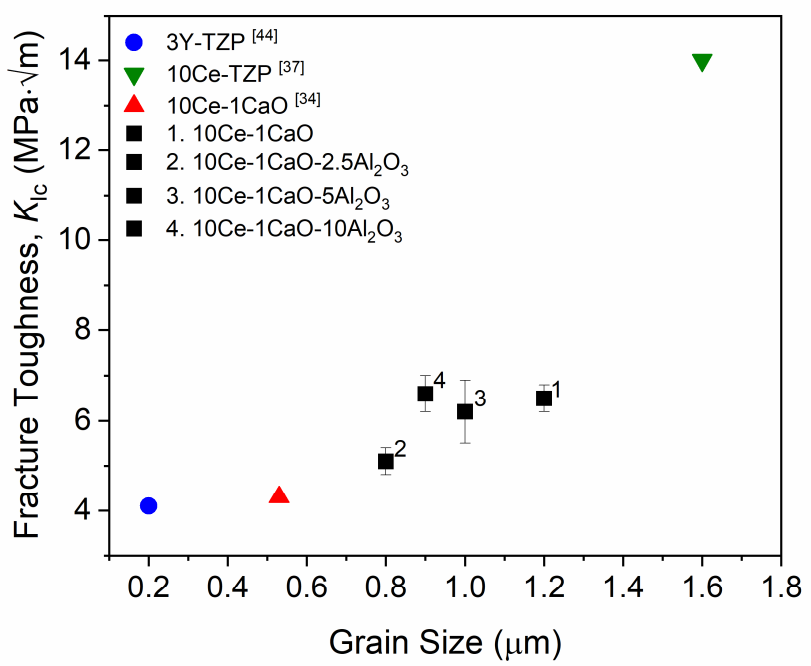

Fig. 6. SEVNB $K_{I c}$ as a function of grain size. The blue fill circle represents 3 Y-TZP ceramics, the green fill inverse tringle represents $10 \mathrm{Ce}$-TZP ceramics, and the red fill triangle represents $10 \mathrm{Ce}-1 \mathrm{CaO}$ based material. To compare, the $K_{I c}$ of these materials was estimated by SEVNB. The reference values were taken from [44], [37], and [34], respectively.

The VIF fracture toughness values for all the samples (including $10 \mathrm{Ce}-1 \mathrm{CaO}-15 \mathrm{Al}_{2} \mathrm{O}_{3}$ ) are shown in Fig. 7. Indentation crack lengths $(l)$ produced with an indentation load of $30 \mathrm{~kg}(294 \mathrm{~N})$ were too short to satisfy the requirements for using Niihara equation for Palmqvist cracks $(0.25<l / a$ $<2.5$, where $a$ is half the length of the average indentation diagonal [24]). So that, the load was increased to $50 \mathrm{~kg}(490 \mathrm{~N})$ to increase the crack lengths to fulfill this condition. As expected, estimated values of $K_{I c}$ by Vickers indentation were higher in comparison to $K_{I c}$ by the SEVNB method. The use of $K_{I c}$ by indentation methods in transformable ceramics could lead to the overestimation of fracture toughness due to the high compressive residual stresses induced by the $t-m$ transformation around Vickers imprints [45-48].

From a qualitative point of view, the results of both methods, VIF and SEVNB, show first a decrease in $K_{I c}$ when adding small concentrations of alumina followed by an increase for higher concentrations. However, the lowest value of indentation $K_{I c}$ is reached for $5 \mathrm{wt} \%$ alumina, while for SEVNB $K_{I c}$, the lowest value is for $2.5 \mathrm{wt} \%$ alumina. This shows that the indentation methods can also give erroneous trends in the evolution of the toughness, an additional reason justifying the need to develop larger size specimens (e.g. notched bars) for the characterization of the fracture toughness of transformable zirconia-based ceramics. 


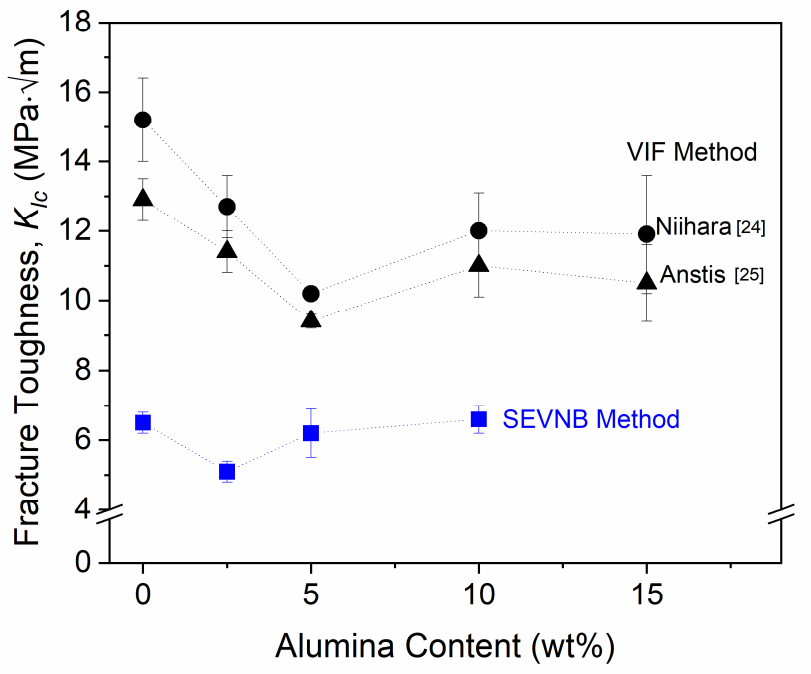

Fig. 7. Fracture toughness as a function of alumina content added to $10 \mathrm{Ce}-1 \mathrm{CaO}$ based composites, measured by VIF (Niihara and Anstis equations) and SEVNB method.

The relationship between the strength and grain size for $10 \mathrm{Ce}-1 \mathrm{CaO}$ base material and its alumina-containing composites is shown in Fig. 8. Once again, the strength for 3Y-TZP, 10Ce$\mathrm{TZP}$, and $10 \mathrm{Ce}-1 \mathrm{CaO}$ base material taken from the literature are also presented as a comparison. In this study, the addition of $1 \mathrm{~mol} \%$ of calcia increases the strength of pure 10Ce-TZP ceramics (for example from $504 \mathrm{MPa}$ in 10Ce-TZP ceramics having a grain size of $1.6 \mu \mathrm{m}$ [37] to $742 \mathrm{MPa}$ in our $10 \mathrm{Ce}-1 \mathrm{CaO}$ material showing a grain size of $1.2 \mu \mathrm{m}$ ). This change in strength can be related to the grain refinement caused by co-doping with calcia and by the increase in the stability of the resulting tetragonal phase. The $10 \mathrm{Ce}-1 \mathrm{CaO}-5 \mathrm{Al}_{2} \mathrm{O}_{3}$ composite presents a similar strength to that of $10 \mathrm{Ce}-1 \mathrm{CaO}$ based ceramic $(739 \mathrm{MPa}$, grain size $1.0 \mu \mathrm{m})$. Previous works have shown that $3 \mathrm{Y}$ TZP ceramics present the highest strength among zirconia ceramics $(>\sim 1000 \mathrm{MPa})$ and also a much finer microstructure (grain size of $0.3 \mu \mathrm{m}$ ) [49]. Regarding $10 \mathrm{Ce}-1 \mathrm{CaO}$ based material, as also shown in Fig. 8, the same ceramic composition elaborated by Turon-Viñas et al. [34] reached a higher strength (922 MPa) and a grain size of $\sim 0.5 \mu \mathrm{m}$. However, it is not easy to directly compare our results to these data because Turon-Viñas et al. [34] have measured the strength by biaxial test, which could lead to an overestimation of the strength due to the material transformability.

In agreement with the fracture toughness values reached in all the materials prepared in the present study (i.e., between 5.1 and $6.6 \mathrm{MPa} \cdot \sqrt{\mathrm{m}}$ ), these ceramics behave as brittle materials [50]. In other words, the mechanism controlling the fracture changes from transformation controlled in pure $10 \mathrm{Ce}-\mathrm{TZP}$ [34] to defect controlled in $10 \mathrm{Ce}-1 \mathrm{CaO}$ and $10 \mathrm{Ce}-1 \mathrm{CaO}$ composites. The behavior of the composites can thus be rationalized by considering the relationship between defect size, $K_{I c}$, and the strength (Griffith theory). The greater grain size refinement observed in $10 \mathrm{Ce}-1 \mathrm{CaO}-$ $2.5 \mathrm{Al}_{2} \mathrm{O}_{3}$ with respect to the other composites induces a decrease in the transformability, hence the reduction of $K_{I c}$, and, therefore, of the strength since fracture initiation is here controlled by defect size and not by the $t-m$ phase transformation. 


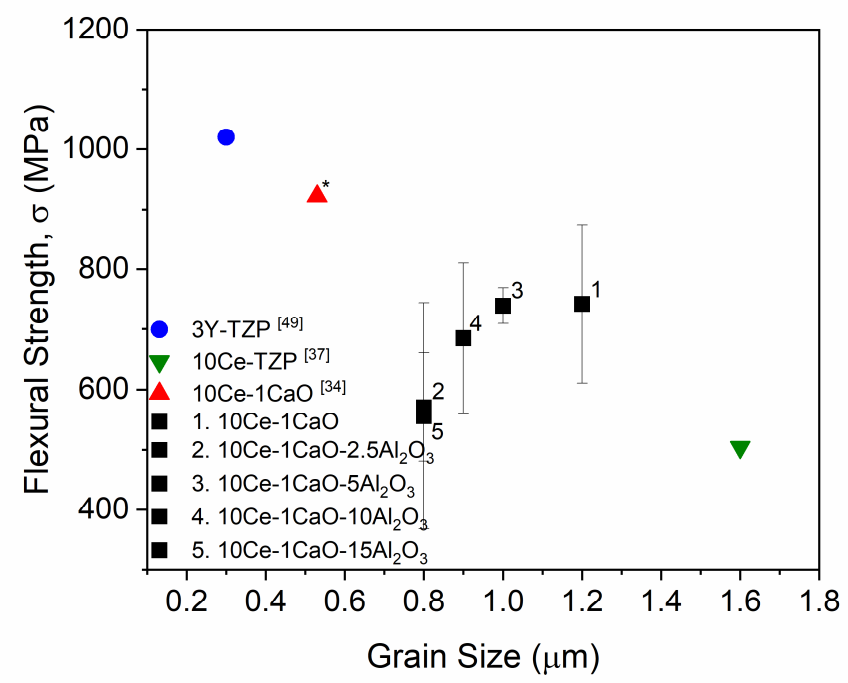

Fig. 8. Three-point flexural strength as a function of grain size. The blue fill circle represents $3 \mathrm{Y}$ TZP ceramics, the green fill inverse tringle represents 10Ce-TZP ceramics, and the red fill triangle represents $10 \mathrm{Ce}-1 \mathrm{CaO}$ based material. To compare, $\sigma$ of these materials was estimated by threepoint flexural strength. The reference values were taken from [49], [37], and [34], respectively.

For higher alumina contents (i.e., 5 and $10 \mathrm{wt} \% \mathrm{Al}_{2} \mathrm{O}_{3}$ composites), the strength slightly increases, in agreement with the very slight increase in $K_{I c}$, always under the hypothesis that the processing defect distribution is similar in both compositions. Finally, there is a large scatter and a decrease in the values for the strength of $10 \mathrm{Ce}-1 \mathrm{CaO}-15 \mathrm{Al}_{2} \mathrm{O}_{3}$. As discussed before, for this composition, $K_{I c}$ was not measured by the SEVNB method. However, from the value VIF $K_{I c}$, one would expect a similar $K_{I c}$ value as for $10 \mathrm{wt} \% \mathrm{Al}_{2} \mathrm{O}_{3}$ composites. Therefore, the drop and scatter in the strength might be associated with the coarser microstructure induced by the agglomeration of alumina particles and larger processing defects. Moreover, the lower elastic modulus value of $167 \mathrm{GPa}$ indicates a greater quantity/size of defects in this composition. As in conventional brittle ceramics, the strength decrease in $10 \mathrm{Ce}-1 \mathrm{CaO}-15 \mathrm{Al}_{2} \mathrm{O}_{3}$ is due above all to the increase in the size of processing defects, as predicted by Griffith's theory.

Finally, for the $10 \mathrm{Ce}-1 \mathrm{CaO}-2.5 \mathrm{Al}_{2} \mathrm{O}_{3}$ composite, the decrease of the strength compared to the matrix (from 742 to $571 \mathrm{MPa}$ ) can be related to the low fracture toughness value achieved in this composite $(5.1 \mathrm{MPa} \cdot \sqrt{\mathrm{m}})$.

To provide an idea of the critical flaw size $\left(a_{c}\right)$ in these ceramics, a simple calculation was made based on the Griffith equation:

$$
K_{I c}=Y \sigma \sqrt{\pi a_{c}}
$$

where $K_{I c}$ is the fracture toughness, $Y$ a geometrical factor approximated to be 1.1215 for a surface crack of length $a_{c}$ and $\sigma$ the flexural strength (see Table 4). 
Table 4. Critical flaw size $\left(a_{c}\right)$ on ceria-calcia stabilized zirconia composites with alumina additions estimated using Griffith equation.

\begin{tabular}{|c|c|c|c|}
\hline Sample & $\begin{array}{l}\text { Fracture Toughness } \\
(\mathrm{MPa} \cdot \sqrt{\mathrm{m}})\end{array}$ & $\begin{array}{l}\text { 3-Point Flexural } \\
\text { Strength }(\mathrm{MPa})\end{array}$ & $\begin{array}{l}\text { Length of critical surface } \\
\text { defect } a_{c}(\mu \mathrm{m})^{* *}\end{array}$ \\
\hline $10 \mathrm{Ce}-1 \mathrm{CaO}$ & 6.5 & 742 & 19 \\
\hline $10 \mathrm{Ce}-1 \mathrm{CaO}-2.5 \mathrm{Al}_{2} \mathrm{O}_{3}$ & 5.1 & 571 & 20 \\
\hline $10 \mathrm{Ce}-1 \mathrm{CaO}-5 \mathrm{Al}_{2} \mathrm{O}_{3}$ & 6.2 & 739 & 18 \\
\hline $10 \mathrm{Ce}-1 \mathrm{CaO}-10 \mathrm{Al}_{2} \mathrm{O}_{3}$ & 6.6 & 685 & 23 \\
\hline $10 \mathrm{Ce}-1 \mathrm{CaO}-15 \mathrm{Al}_{2} \mathrm{O}_{3}$ & $6.2-6.6^{*}$ & 556 & $31-36$ \\
\hline
\end{tabular}

Critical defect sizes around $20 \mu \mathrm{m}$ were estimated in $10 \mathrm{Ce}-1 \mathrm{CaO}$ and its composites containing $2.5,5$ and $10 \mathrm{wt} \%$ of alumina, corroborating the hypothesis that the decrease of the strength with the addition of $2.5 \mathrm{wt} \%$ of alumina is related to the lower transformability of zirconia due to the grain refinement and not to a flaw size increase. In composites containing $15 \mathrm{wt} \%$ of alumina, the size of the critical defect was higher $(>30 \mu \mathrm{m})$. As discussed earlier, we have observed that the pressability of as-prepared powders decreased with the addition of alumina and that it was especially critical for $15 \mathrm{wt} \% \mathrm{Al}_{2} \mathrm{O}_{3}$. The processing step of these materials should be further improved. As the maximum sustainable stress is here ruled by flaw propagation, the strength of these type of composites is therefore strongly affected by the size of the processing flaws.

\subsubsection{Low Temperature Degradation (LTD)}

The monoclinic phase evolution during the accelerated aging tests is shown in Fig. 9. As reminder, XRD was performed in polished $10 \mathrm{Ce}-1 \mathrm{CaO}$ and its alumina-containing composites. For $10 \mathrm{Ce}-$ $1 \mathrm{CaO}$, no phase transformation was observed either after polishing or after 60 hours of testing. For the other materials, a low content of monoclinic phase $(<7 \mathrm{vol} \%)$ was transformed during polishing, and only a limited transformed monoclinic phase $(<3.6$ vol\%) was observed after 60 hours of testing. This behavior demonstrates the excellent aging resistance of these ceramics.

Similar aging results were obtained in composite samples of the same composition (10Ce-1CaO based ceramics) studied in previous work [27]. By using the rough criteria that 60 hours of accelerated aging in autoclave represents $180-240$ years in-vivo at $37^{\circ} \mathrm{C}$, it is clear that the materials here developed are enough aging resistant to meet the stability characteristics required in biomedical applications. As a reminder, to allow the implantation of a zirconia-based material into the human body, the ISO standard 13356 recommends applying only 5 hours of accelerated aging in an autoclave $\left(134^{\circ} \mathrm{C}, 2\right.$ bars) and obtaining less than $25 \%$ of transformed monoclinic phase. Finally, it should be emphasized here that 10Ce-TZP pure ceramics subjected to 70 hours of accelerated aging do not aged [51], corroborating that the addition of calcia as a co-stabilizer and the resulting oxygen vacancies have only a little impact on the aging resistance of $10 \mathrm{Ce}-1 \mathrm{CaO}$ based materials (less than 3.6 vol\% of transformation after 60 hours of test). 


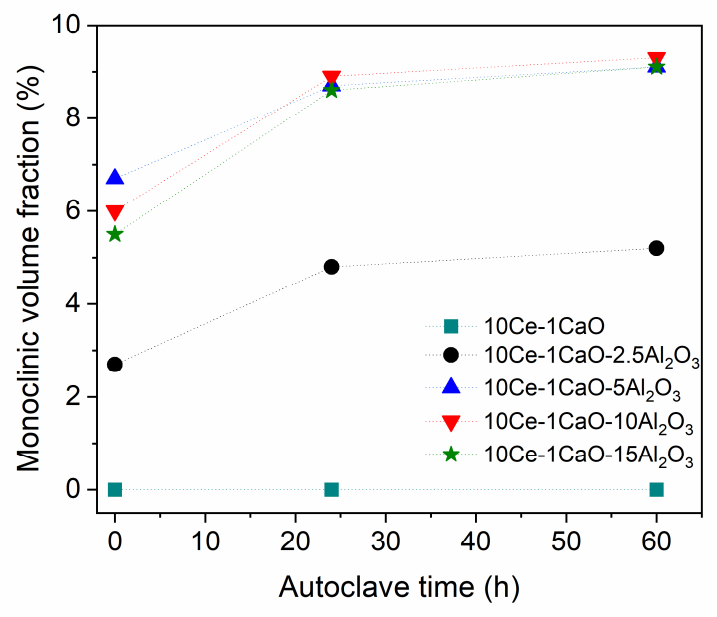

Fig. 9. Monoclinic volume fraction as a function of accelerated aging time. The accelerated aging test was done in an autoclave at $134^{\circ} \mathrm{C}$ and 2 bars.

\subsubsection{Final considerations and perspectives}

In order to prepare a new type of highly aging resistance zirconia-based ceramics for structural biomedical applications, Ce-TZP can be used if its strength, usually reaching 500-600 MPa, is improved. For doing that, the $t-m$ phase transformability could be adapted by modifying both the amount of stabilizer $\left(\mathrm{CeO}_{2}\right)$ and the zirconia grain size. Moreover, the size of the processing defects must also be decreased. One way to refine the microstructure of Ce-TZP ceramics is to make composites, for example, by adding secondary phases such as alumina and/or aluminates [32]. The most significant work done in this area was published in 1998 by Nawa et al. [30]. These authors developed a 10Ce-TZP-based composite $\left(10 \mathrm{~mol} \% \mathrm{CeO}_{2}\right.$, zirconia grain size of $0.6 \mu \mathrm{m}$ ) containing $30 \mathrm{vol} \%$ of $\mathrm{Al}_{2} \mathrm{O}_{3}$ particles and characterized by impressive values of strength and $K_{I c}$ (950 MPa by three-points bending and $9.8 \mathrm{MPa} \cdot \sqrt{ } \mathrm{m}$ by SEVNB, respectively). Later, this material was optimized and patented under the trademark NanoZr ${ }^{\circledR}$ (Panasonic Electric Works, Japan), and it has become a real benchmark in the field of Ce-TZP-based composites. Other researchers have developed Ce-TZP triphasic-based composites (see Table 1). In comparison with $\mathrm{NanoZr}^{\mathrm{B}}$, these tri-phasic composites exhibit a slightly larger zirconia grain size $(0.9 \mu \mathrm{m})$, lower values of strength $\left(559 \mathrm{MPa}\right.$ by three-points bending), relatively higher $K_{I c}(10.2 \mathrm{MPa} \cdot \sqrt{\mathrm{m}}$ by SEVNB) and ductile behavior $[32,28]$. Another way to refine the microstructure of Ce-TZP ceramics is to co-stabilize it with calcia $(\mathrm{CaO})$. It has been shown that the addition of only $1 \mathrm{~mol} \%$ of calcia reduces effectively the zirconia grain size (thus increasing the strength and hardness) but also makes the tetragonal phase more stable, thus decreasing the quantity of $t-m$ phase transformation under stress [34]. In the present work, we have combined both approaches in order to develop ceria-calcia zirconia-based composites containing alumina particles.

The $K_{I c}$ values for the ceramic matrix $(10 \mathrm{Ce}-1 \mathrm{CaO})$ and its composites were very close (in the range 6.2-6.6 $\mathrm{MPa} \cdot \sqrt{\mathrm{m}})$ except for the $2.5 \mathrm{wt} \%$ alumina composition $\left(5.1 \mathrm{MPa} \cdot V_{\mathrm{m}}\right)$. Such $K_{I c}$ values corroborate the brittle behavior characterizing these ceramics $10 \mathrm{Ce}-1 \mathrm{CaO}$ zirconia-based materials in contrast to the ductile one characterizing 10Ce-TZP ceramics. This change from ductile to brittle results from a greater stabilization of the tetragonal phase by the addition of calcia. Even if the actual content of calcia entering in solid-solution needs to be better characterized, it seems to have a very strong effect on the stabilization of the tetragonal phase 
through the incorporation of oxygen vacancies (calcium being bivalent and replacing tetravalent zirconium) and the microstructural refinement.

For comparison, the $K_{I c}$ of pure ductile behaving $10 \mathrm{Ce}-\mathrm{TZP}$ is about $15-20 \mathrm{MPa} \cdot V_{\mathrm{m}}$ [52]. In the case of our materials, the best combination of strength and $K_{I c}$ is observed in $10 \mathrm{Ce}-1 \mathrm{CaO}(742 \pm$ $131 \mathrm{MPa}$ and $6.5 \pm 0.3 \mathrm{MPa} \cdot V_{\mathrm{m}}$, respectively) and $10 \mathrm{Ce}-1 \mathrm{CaO}-5 \mathrm{Al}_{2} \mathrm{O}_{3}$ composite $(739 \pm 30 \mathrm{MPa}$ and $6.2 \pm 0.7 \mathrm{MPa} \cdot \sqrt{\mathrm{m}}$, respectively). Although these mechanical characteristics are very similar, compared to the pure matrix, the addition of $5 \mathrm{wt} \% \mathrm{Al}_{2} \mathrm{O}_{3}$ also makes it possible to slightly increase the hardness of the material and to reduce the variability of the strength (i.e., the standard deviation).

It is worth noticing that if $K_{I c}$ is measured by VIF methods, the values obtained (between 10 and $16 \mathrm{MPa} \cdot \sqrt{\mathrm{m}}$ ) are overestimated. It is important to recall that the VIF method has many drawbacks for characterizing $K_{I c}$ in transformable ceramics, as indentation residual stresses are partially released as phase transformation occurs, and, consequently, the energy released by crack propagation is much lower than that predicted by the model, resulting in higher $K_{I c}$ values. While this limitation is generally understood, it is also true that, sometimes, high values of $K_{I c}$ measured by VIF are reported in the literature without a further appraisal. Nevertheless, the VIF method is still a method giving sometimes a reasonable qualitative comparison of toughness between similar materials.

From a microstructural point of view, the duplex alumina grains obtained here have indirectly demonstrated the importance of the zirconia grain size on the mechanical behavior of this type of ceramics, thanks to the limitation of the pinning effect and the greater grain growth obtained, in comparison with our previous works. Recently, it has been shown that the toughness of ceramics can be improved in duplex ceramics because a larger residual stress field is induced by the introduction of bigger second phase grains [42]. In our work, the contribution of large alumina particles on toughening the ceramics by promoting the crack deflection still needs to be studied in-depth, for example performing R-curve analyzes. Finally, for better studying the strengthtoughness relationship on ceria-calcia co-stabilized zirconia-based ceramics and composites, it will be necessary to reduce the "stabilization degree" of the tetragonal phase to move towards the ductile domain.

\section{Conclusions}

The present work studied the impact of the density, microstructural features, and mechanical behavior of $10 \mathrm{Ce}-1 \mathrm{CaO}$ zirconia-based composites containing different alumina content ( 0 to 15 wt $\left.\% \mathrm{Al}_{2} \mathrm{O}_{3}\right)$.

Compared to other works where $10 \mathrm{Ce}-1 \mathrm{CaO}$ based composites were developed, our materials exhibited a lower reduction in the zirconia grain size, related to the duplex microstructure developed and good mechanical properties ( $K_{I c}$, strength and hardness). In addition, the densification of ceramics prepared here has been improved compared to composites having the same composition and characterized in our previous works.

Fracture toughness measurements using SEVNB method gave more accurate values and tendencies than indentation ones; hence, it is recommended to characterize this type of transformable zirconia-based ceramics by SEVNB. Likewise, the use of four- and three-point bending tests should be preferred for strength characterization. Thanks to these measurements, we have corroborated the brittle behavior of $10 \mathrm{Ce}-1 \mathrm{CaO}$ zirconia-based ceramics resulting from a higher tetragonal phase stabilization. 
The best combination of mechanical properties was obtained in highly dense $(99.9 \%)$ and micronsized $10 \mathrm{Ce}-1 \mathrm{CaO}-5 \mathrm{Al}_{2} \mathrm{O}_{3}$ composites (zirconia grain size $1.0 \mu \mathrm{m}$ ) that combined an excellent strength $(739 \pm 30 \mathrm{MPa}), K_{\text {Ic }}(6.2 \mathrm{MPa} \cdot \sqrt{\mathrm{m}})$, and hardness $(10.2 \mathrm{GPa})$.

As regards as low temperature degradation, $10 \mathrm{Ce}-1 \mathrm{CaO}$ based ceramics and its aluminacontaining composites presented high aging resistance. The relative increase in the monoclinic phase was below $\sim 4$ vol\% after a long-accelerated aging test of 60 hours $\left(134^{\circ} \mathrm{C}, 2\right.$ bars). This means that these ceramics meet the stability requirements for biomedical applications.

To further increase the strength and fracture toughness in $10 \mathrm{Ce}-1 \mathrm{CaO}$ based composites it is necessary to move towards the ductile domain, in other words to increase the transformability of the tetragonal phase. This could be accomplished by decreasing the ceria content $(<10 \mathrm{~mol} \%)$ while leaving the calcia composition constant $(1 \mathrm{~mol} \%)$ or by keeping the quantity of ceria constant (10 mol\%) and varying the concentration of calcia (between $0-1 \mathrm{~mol} \%$ ). A compromise must be found between the grain size (therefore the alumina content and grain sizes) and the transformability of the material (ceria and calcia composition) in order to optimize both strength and toughness. Further study of the advantages provided by the presence of the coarse grains of alumina over the fracture toughness of the material should also be undertaken.

\section{Acknowledgments}

The authors are grateful to the JECS Trust for funding the research stay of Ms. D. Tovar-Vargas in the MATEIS laboratory of INSA-Lyon (Contract 2019226). The authors want to thank the "Ministerio de Economia y Competitividad" of Spain within the Nacional Plan Project MAT2014-60720-R for the financial support as well as the fellowship BES-2015-075036 awarded to D. Tovar-Vargas. Besides, the authors want to thank Dr. Kitai Makoto of Daiichi Kigensu Kagaku Kogyo Co. for supplying the commercial 10Ce-TZP zirconia powder used as raw material.

\section{References}

[1] R.C. Garvie, R.H. Hannink, R.T. Pascoe, Ceramic steel?, Nature. 258 (1975) 703-704.

[2] J. Chevalier, L. Gremillard, S. Deville, Low-Temperature Degradation of Zirconia and Implications for Biomedical Implants, Annu. Rev. Mater. Res. 37 (2007) 1-32. https://doi.org/doi:10.1146/annurev.matsci.37.052506.084250.

[3] J.A. Muñoz-Tabares, E. Jiménez-Piqué, M. Anglada, Subsurface evaluation of hydrothermal degradation of zirconia, Acta Mater. 59 (2011) 473-484. https://doi.org/10.1016/j.actamat.2010.09.047.

[4] E. Jiménez-Piqué, A. Ramos, J.A. Muñoz-Tabares, A. Hatton, F. Soldera, F. Mücklich, M. Anglada, Focused ion beam tomography of zirconia degraded under hydrothermal conditions, J. Eur. Ceram. Soc. 32 (2012) 2129-2136. https://doi.org/10.1016/j.jeurceramsoc.2012.02.011.

[5] Y. Gaillard, E. Jiménez-Piqué, F. Soldera, F. Mücklich, M. Anglada, Quantification of hydrothermal degradation in zirconia by nanoindentation, Acta Mater. 56 (2008) 4206- 
4216. https://doi.org/10.1016/j.actamat.2008.04.050.

[6] J. Chevalier, L. Gremillard, Ceramics for medical applications: A picture for the next 20 years, J. Eur. Ceram. Soc. 29 (2009) 1245-1255.

https://doi.org/10.1016/j.jeurceramsoc.2008.08.025.

[7] J. Chevalier, L. Gremillard, Zirconia as a biomaterial, Compr. Biomater. 1 (2017) 122144. https://doi.org/10.1016/b978-0-12-803581-8.10245-0.

[8] J. Chevalier, What future for zirconia as a biomaterial?, Biomaterials. 27 (2006) 535543. https://doi.org/10.1016/j.biomaterials.2005.07.034.

[9] E. Roitero, F. Lasserre, M. Anglada, F. Mücklich, E. Jiménez-Piqué, A parametric study of laser interference surface patterning of dental zirconia: Effects of laser parameters on topography and surface quality, Dent. Mater. 33 (2017) e28-e38.

https://doi.org/10.1016/j.dental.2016.09.040.

[10] J. Chevalier, A. Liens, H. Reveron, et al., Forty years after the promise of «ceramic steel?»: Zirconia-based composites with a metal-like mechanical behavior, J. Am. Ceram. Soc. 103 (2020) 1482-1513. https://doi.org/10.1111/jace.16903.

[11] K. Niihara, New design concept of structural ceramics. Ceramic nanocomposites, J. Ceram. Soc. Japan. Int. Ed. 99 (1991) 945-952.

[12] J.D. Kuntz, G. Zhan, A.K. Mukherjee, Nanocrystalline-Matrix Ceramic Composites for Improved Fracture, Mater. Res. Soc. 29 (2004) 22-27.

[13] S. Hwang, I. Chen, Grain Size Control of Tetragonal Zirconia Polycrystals Using the Space Charge Concept, J. Am. Ceram. Soc. 73 (1990) 3269-3277.

https://doi.org/10.1111/j.1151-2916.1990.tb06449.x.

[14] T. Onda, K. Okazaki, H. Suematsu, H. Yamauchi, M. Hayakawa, Effect of divalent elements on the grain growth of TZP, Mater. Sci. Forum. 304-306 (1999) 471-476. https://doi.org/10.4028/www.scientific.net/msf.304-306.471.

[15] D.B. Marshall, R.F. Cook, N.P. Padture, M.L. Oyen, A. Pajares, J.E. Bradby, I.E. Reimanis, R. Tandon, T.F. Page, G.M. Pharr, B.R. Lawn, The Compelling Case for Indentation as a Functional Exploratory and Characterization Tool, J. Am. Ceram. Soc. 98 (2015) 2671-2680. https://doi.org/10.1111/jace.13729.

[16] N. Cuadrado, D. Casellas, M. Anglada, E. Jiménez-Piqué, Evaluation of fracture toughness of small volumes by means of cube-corner nanoindentation, Scr. Mater. 66 (2012) 670-673. https://doi.org/10.1016/j.scriptamat.2012.01.033.

[17] G.D. Quinn, R.C. Bradt, On the Vickers Indentation Fracture Toughness Test, J. Am. Ceram. Soc. 90 (2007) 673-680. https://doi.org/10.1111/j.1551-2916.2006.01482.x.

[18] N. Cuadrado, J. Seuba, D. Casellas, M. Anglada, E. Jiménez-Piqué, Geometry of nanoindentation cube-corner cracks observed by FIB tomography: Implication for fracture resistance estimation, J. Eur. Ceram. Soc. 35 (2015) 2949-2955. https://doi.org/10.1016/j.jeurceramsoc.2015.03.031.

[19] P.F. Cesar, A. Della Bona, S.S. Scherrer, M. Tholey, R. van Noort, A. Vichi, R. Kelly, U. Lohbauer, ADM guidance-Ceramics: Fracture toughness testing and method selection, Dent. Mater. 33 (2017) 575-584. https://doi.org/10.1016/j.dental.2017.03.006.

[20] J.F. Tsai, U. Chon, N. Ramachandran, D.K. Shetty, Transformation Plasticity and Toughening in CeO2-Partially-Stabilized Zirconia-Alumina (Ce-TZP/Al203)

Composites Doped with MnO, J. Eur. Ceram. Soc. 75 (1992) 1229-1238.

https://doi.org/doi.org/10.1111/j.1151-2916.1992.tb05562.x. 
[21] R.A. Cutler, R.J. Mayhew, K.M. Prettyman, A. V. Virkar, High-Toughness CeTZP/A12O3 Ceramics with Improved Hardness and Strength, J. Am. Ceram. Soc. 74 (1991) 179-186. https://doi.org/10.1111/j.1151-2916.1991.tb07315.x.

[22] D. Casellas, M.M. Nagl, L. Llanes, M. Anglada, Fracture toughness of alumina and ZTA ceramics: Microstructural coarsening effects, J. Mater. Process. Technol. 143-144 (2003) 148-152. https://doi.org/10.1016/S0924-0136(03)00396-0.

[23] A. Şakar-Deliormanli, M. Güden, Microhardness and fracture toughness of dental materials by indentation method, J. Biomed. Mater. Res. - Part B Appl. Biomater. 76 (2006) 257-264. https://doi.org/10.1002/jbm.b.30371.

[24] K. Niihara, R. Morena, D.P.H. Hasselman, Evaluation of KIc of brittle solids by the indentation method with low crack-to-indent ratios, J. Mater. Sci. Lett. 1 (1982) 13-16. https://doi.org/10.1007/BF00724706.

[25] G.R. Anstis, P. Chantikul, B.R. Lawn, D.B. Marshal, A Critical Evaluation of Indentation Techniques for Measuring Fracture Toughness: I, Direct Crack Measurements, J. Am. Ceram. Soc. 64 (1981) 533-538. https://doi.org/10.1111/j.11512916.1981.tb10320.x.

[26] K. Strecker, S. Ribeiro, M.-J. Hoffmann, Fracture toughness measurements of LPS-SiC: a comparison of the indentation technique and the SEVNB method, Mater. Res. 8 (2005) 121-124. https://doi.org/10.1590/S1516-14392005000200004.

[27] D. Tovar-Vargas, M. Turon-Vinas, M. Anglada, E. Jimenez-Pique, Enhancement of mechanical properties of ceria-calcia stabilized zirconia by alumina reinforcement, J. Eur. Ceram. Soc. 40 (2020) 3714-3722. https://doi.org/10.1016/j.jeurceramsoc.2020.02.002.

[28] I. Touaiher, M. Saâdaoui, J. Chevalier, L. Preiss, H. Reveron, Fracture behavior of CeTZP/alumina/aluminate composites with different amounts of transformation toughening. Influence of the testing methods, J. Eur. Ceram. Soc. 38 (2018) 1778-1789. https://doi.org/10.1016/j.jeurceramsoc.2017.09.052.

[29] T. Sato, T. Endo, M. Shimada, Postsintering Hot Isostatic Pressing of Ceria-Doped Tetragonal Zirconia/Alumina Composites in an Argon-Oxygen Gas Atmosphere, J. Am. Ceram. Soc. 72 (1989) 761-764. https://doi.org/10.1111/j.1151-2916.1989.tb06213.x.

[30] M. Nawa, S. Nakamoto, T. Sekino, K. Niihara, Tough and Strong Ce-TZP/Alumina Nanocomposites Doped with Titania, Ceram. Int. 24 (1998) 497-506. https://doi.org/10.1016/S0272-8842(97)00048-5.

[31] K. Tanaka, J. Tamura, K. Kawanabe, M. Nawa, M. Oka, M. Uchida, T. Kokubo, T. Nakamura, Ce-TZP/Al2O3 nanocomposite as a bearing material in total joint replacement, J. Biomed. Mater. Res. 63 (2002) 262-270. https://doi.org/10.1002/jbm.10182.

[32] H. Reveron, M. Fornabaio, P. Palmero, T. Fürderer, E. Adolfsson, V. Lughi, A. Bonifacio, V. Sergo, L. Montanaro, J. Chevalier, Towards long lasting zirconia-based composites for dental implants: Transformation induced plasticity and its consequence on ceramic reliability, Acta Biomater. 48 (2017) 423-432. https://doi.org/10.1016/j.actbio.2016.11.040.

[33] D. Tovar-Vargas, B. Ferrari, A.J. Sanchez-Herencia, M. Anglada, E. Jimenez-Pique, Low Temperature Degradation and Mechanical Properties of Alumina Reinforced CeriaZirconia by Colloidal Processing, J. Eur. Ceram. Soc. 41 (2021) 1459-1470. https://doi.org/10.1016/j.jeurceramsoc.2020.09.031.

[34] M. Turon-Vinas, F. Zhang, J. Vleugels, M. Anglada, Effect of calcia co-doping on ceria- 
stabilized zirconia, J. Eur. Ceram. Soc. 38 (2018) 2621-2631.

https://doi.org/10.1016/j.jeurceramsoc.2017.12.053.

[35] P. Palmero, M. Fornabaio, L. Montanaro, H. Reveron, C. Esnouf, J. Chevalier, Towards long lasting zirconia-based composites for dental implants: Part I: Innovative synthesis, microstructural characterization and in vitro stability, Biomaterials. 50 (2015) 38-46. https://doi.org/10.1016/j.biomaterials.2015.01.018.

[36] J.C. Wurst, J.A. Nelson, Lineal Intercept Technique for Measuring Grain Size in TwoPhase Polycrystalline Ceramics, J. Am. Ceram. Soc. 46 (1972) 1972. https://doi.org/doi.org/10.1111/j.1151-2916.1972.tb11224.x.

[37] H. El Attaoui, Influence du renforcement sur le comportement en fatigue statique et cyclique des céramiques monolithiques de type Alumine et Zircone, PhD. Thesis, INSA Lyon. France, 2003.

[38] ISO 6872-Dentistry-ceramic materials, ISO 6872, 2015.

[39] R.C. Garvie, P.S. Nicholson, Phase Analysis in Zirconia Systems, J. Am. Ceram. Soc. 55 (1972) 303-305. https://doi.org/10.1111/j.1151-2916.1972.tb11290.x.

[40] H. Toraya, M. Yoshimura, S. Somiya, Quantitative Analysis of Monoclinic-Stabilized Cubic ZrO2 Systems by X-Ray Diffraction, J. Am. Ceram. Soc. 67 (1984) C-183-C-184. https://doi.org/10.1111/j.1151-2916.1984.tb19614.x.

[41] S. Deville, L. Gremillard, J. Chevalier, G. Fantozzi, A critical comparison of methods for the determination of the aging sensitivity in biomedical grade yttria-stabilized zirconia, J. Biomed. Mater. Res. - Part B Appl. Biomater. 72 (2005) 239-245. https://doi.org/10.1002/jbm.b.30123.

[42] J. Zou, H. Bin Ma, J.J. Liu, W.M. Wang, G.J. Zhang, Z.Y. Fu, Nanoceramic composites with duplex microstructure break the strength-toughness tradeoff, J. Mater. Sci. Technol. 58 (2020) 1-9. https://doi.org/10.1016/j.jmst.2020.05.014.

[43] P. Palmero, Structural Ceramic Nanocomposites: A Review of Properties and Powders' Synthesis Methods, Nanomaterials. 5 (2015) 656-696.

https://doi.org/10.3390/nano5020656.

[44] F. Zhang, K. Vanmeensel, M. Inokoshi, M. Batuk, J. Hadermann, B. Van Meerbeek, I. Naert, J. Vleugels, Critical influence of alumina content on the low temperature degradation of 2-3mol\% yttria-stabilized TZP for dental restorations, J. Eur. Ceram. Soc. 35 (2015) 741-750. https://doi.org/10.1016/j.jeurceramsoc.2014.09.018.

[45] D. Ćorić, L. Ćurković, M.M. Renjo, Statistical analysis of vickers indentation fracture toughness of Y-TZP ceramics, Trans. Famena. 41 (2017) 1-16. https://doi.org/10.21278/TOF.41201.

[46] S. Scherrer, I. Denry, H. Wiskott, Comparison of three fracture toughness testing techniques using a dental glass and a dental ceramic, Dent. Mater. 14 (1998) 246-255. https://doi.org/10.1016/S0109-5641(98)00032-3.

[47] M. Nawa, K. Yamada, N. Kurizoe, Effect of the t-m transformation morphology and stress distribution around the crack path on the measured toughness of zirconia ceramics: A case study on Ce-TZP/alumina nanocomposite, J. Eur. Ceram. Soc. 33 (2013) 521529. https://doi.org/10.1016/j.jeurceramsoc.2012.10.007.

[48] R. Benzaid, J. Chevalier, M. Saâdaoui, G. Fantozzi, M. Nawa, L.A. Diaz, R. Torrecillas, Fracture toughness, strength and slow crack growth in a ceria stabilized zirconia-alumina nanocomposite for medical applications, Biomaterials. 29 (2008) 3636-3641. https://doi.org/10.1016/j.biomaterials.2008.05.021. 
[49] M. Trunec, Effect of grain size on mechanical properties of 3Y-TZP ceramics, Ceram. Silikaty. 52 (2008) 165-171.

[50] M. V. Swain, L.R.F. Rose, Strength Limitations of Transformation-Toughened Zirconia Alloys, J. Am. Ceram. Soc. 69 (1986) 511-518. https://doi.org/10.1111/j.11512916.1986.tb04785.x.

[51] J. Chevalier, L. Gremillard, A. V. Virkar, D.R. Clarke, The tetragonal-monoclinic transformation in zirconia: Lessons learned and future trends, J. Am. Ceram. Soc. 92 (2009) 1901-1920. https://doi.org/10.1111/j.1551-2916.2009.03278.x.

[52] H. El Attaoui, M. Saâdaoui, J. Chevalier, G. Fantozzi, Static and cyclic crack propagation in Ce-TZP ceramics with different amounts of transformation toughening, J. Eur. Ceram. Soc. 27 (2007) 483-486.

https://doi.org/10.1016/j.jeurceramsoc.2006.04.108. 